\title{
Plate interaction in the NE Caribbean subduction zone from continuous GPS observations
}

\author{
Uri S. ten Brink ${ }^{1}$ and Alberto M. López-Venegas ${ }^{2}$ \\ Received 23 February 2012; revised 19 April 2012; accepted 21 April 2012; published 19 May 2012.
}

[1] Kinematic similarities between the Sumatra and Puerto Rico Trenches highlight the potential for a mega-earthquake along the Puerto Rico Trench and the generation of local and trans-Atlantic tsunamis. We used the horizontal components of continuous GPS (cGPS) measurements from 10 sites on NE Caribbean islands to evaluate strain accumulation along the North American (NA) - Caribbean (CA) plate boundary. These sites move westward and slightly northward relative to $\mathrm{CA}$ interior at rates $\leq 2.5 \mathrm{~mm} / \mathrm{y}$. Provided this motion originates in the subduction interface, the northward motion suggests little or no trench-perpendicular thrust accumulation and may in fact indicate divergence north of Puerto Rico, where abnormal subsidence, bathymetry, and gravity are observed. The Puerto Rico Trench, thus, appears unable to generate mega-earthquakes, but damaging smaller earthquakes cannot be discounted. The westward motion, characterized by decreasing rate with distance from the trench, is probably due to eastward motion of CA plate impeded at the plate boundary by the Bahamas platform. Two additional cGPS sites in Mona Passage and SW Puerto Rico move to the SW similar to Hispaniola and unlike the other 10 sites. That motion relative to the rest of Puerto Rico may have given rise to seismicity and normal faults in Mona Rift, Mona Passage, and SW Puerto Rico. Citation: ten Brink, U. S., and A. M. López-Venegas (2012), Plate interaction in the NE Caribbean subduction zone from continuous GPS observations, Geophys. Res. Lett., 39, L10304, doi:10.1029/2012GL051485.

\section{Introduction}

[2] Driven by plate motion, elastic strain accumulates in locked parts of the interface between a subducting plate and an overlying plate. This strain is released when the interface ruptures during an earthquake. Therefore the rate and location of elastic strain accumulation are of great interest for earthquake hazard mitigation and for understanding earthquake physics. Approaches to estimating the rate and location of elastic strain accumulation at subduction zones include measuring the rates of vertical and horizontal deformations landward of the subduction zone [Savage, 1983] using tide gauges, leveling, paleo-shoreline markers,

\footnotetext{
${ }^{1}$ Woods Hole Science Center, U.S. Geological Survey, Woods Hole, Massachusetts, USA.

${ }^{2}$ Department of Geology, University of Puerto Rico, Mayagüez, Puerto Rico.

Corresponding author: U. S. ten Brink, Woods Hole Science Center, U.S. Geological Survey, 384 Woods Hole Rd., Woods Hole, MA 02543-1598, USA. (utenbrink@usgs.gov)

This paper is not subject to U.S. copyright.

Published in 2012 by the American Geophysical Union.
}

and most commonly Global Positioning System (GPS) geodesy [e.g., Prawirodirdjo et al., 1997].

[3] The Puerto Rico Trench is an 800-km-long curved subduction zone that wraps around the NE corner of the Caribbean (CA) plate (Figure 1). According to a mix of GPS and geological data, the North American (NA) plate subducts under the CA plate at a rate of $20.0 \pm 0.4 \mathrm{~mm} / \mathrm{y}$ along an azimuth of $254 \pm 1^{\circ}$ [DeMets et al., 2010]. Subduction is thus highly oblique $\left(\geq 10^{\circ}\right)$ to the NA-CA plate boundary, similar to that along Sumatra subduction zone. Following the 2004 Sumatra earthquake and tsunami, concern grew that the Puerto Rico Trench might be capable of producing a similar mega-earthquake, which could cause severe destruction by ground shaking, tsunamis striking nearby islands, as well as transoceanic tsunamis that could affect the U.S. East Coast [Geist and Parsons, 2009] and Europe. There is no clear historical or instrumental record for large earthquakes along the NE Caribbean subduction zone except for 20th century earthquakes north of the Dominican Republic and Mona Passage (Figure 1) [ten Brink et al., 2011]. Tsunami deposits dated at 1650-1800 A.D. were found on Anegada, British Virgin Islands, but their source is presently debated [Atwater et al., 2012].

[4] To evaluate the seismic potential of the Puerto Rico Trench, we analyze the velocity field recorded by 13 continuous GPS (cGPS) stations in the Lesser Antilles, the British and U.S. Virgin Islands, and Puerto Rico (Figure 1 and Table S1 in the auxiliary material), and we model these data using an elastic backslip model [Savage, 1983]. ${ }^{1}$ The backslip model assumes that a down-dip portion of the subduction interface is fully or partially locked during the interseismic period, causing the downgoing slab to drag the overlying forearc and arc in the direction of subduction. Locking is estimated by imposing motion in the direction of subduction on the bottom of the upper plate and comparing the calculated velocities at the GPS sites to the GPS observations. This approach was taken in other subduction zones around the world [Dixon, 1993; Norabuena et al., 1998; Hashimoto et al., 2009].

[5] Manaker et al. [2008] divided the NE Caribbean into rigid blocks and simultaneously inverted for elastic strain accumulation on the plate boundary and on block boundary faults. Their goal was to estimate velocities along the major strike-slip fault zones traversing Hispaniola, where they had dense coverage of campaign GPS data. We elected to focus on the subduction interface, because GPS velocities in Puerto Rico, the Virgin Islands, and St. Maarten decrease gradually with distance from the plate boundary (Figure 1b), which implies continuous deformation of the upper plate.

\footnotetext{
${ }^{1}$ Auxiliary materials are available in the HTML. doi:10.1029/ 2012 GL051485
} 

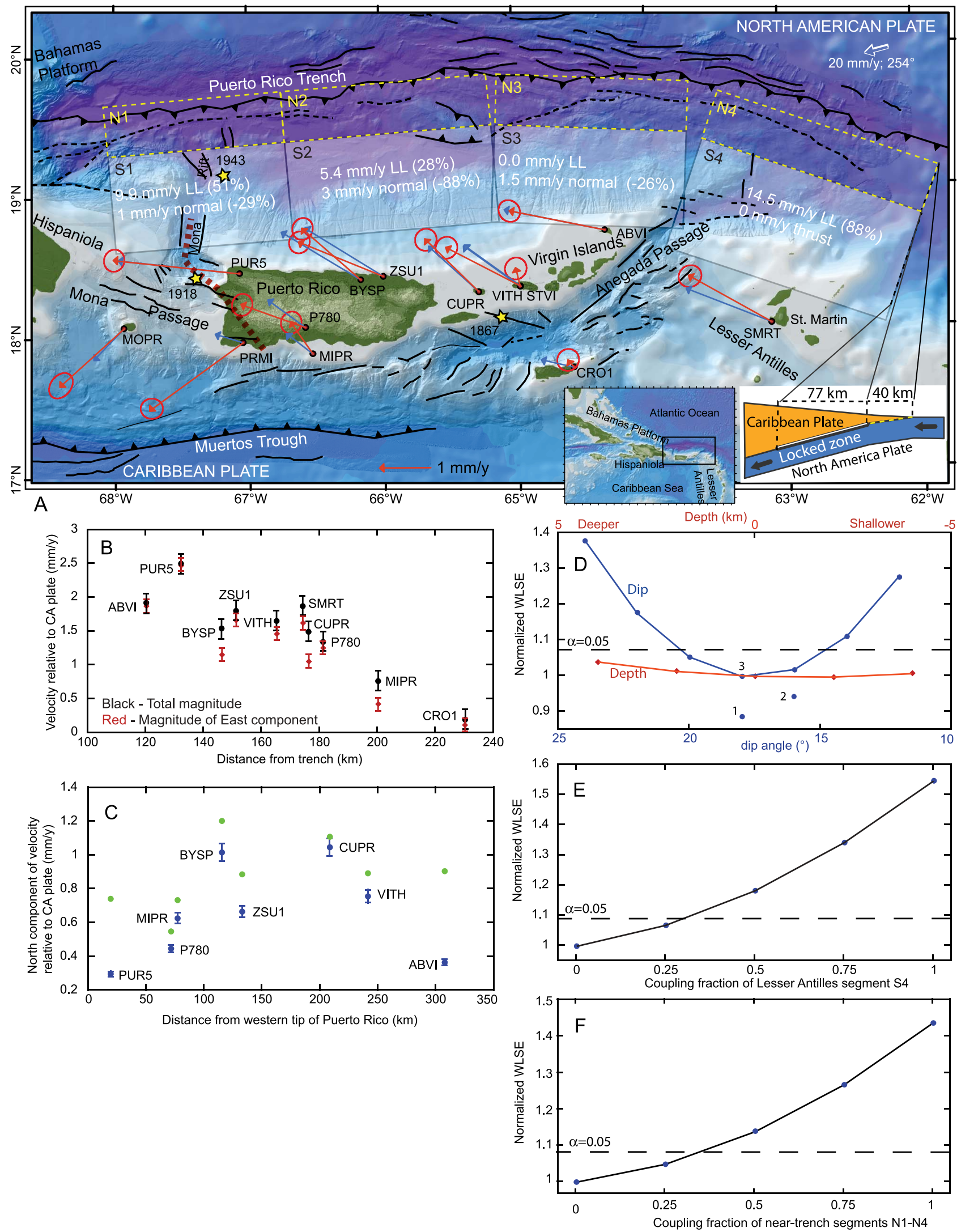

Figure 1 
Our goal is also different, to evaluate the separate components of stress loading at the subduction interface from the observed GPS velocities on the upper plate.

\section{Data}

[6] Data from 13 continuously operated GPS stations in the NE Caribbean were obtained from the UNAVCO archive for a period of 2.75-5 years ending in August 2011 at sampling rates of 10,15 or $30 \mathrm{~s}$ with only a few periods of interruption. Although campaign GPS data were collected in this region during the late 1990s [Jansma et al., 2000; Jansma and Mattioli, 2005], this dataset is not freely available. The data were processed and analyzed using GIPSY-OASIS II release version 6 [Zumberge et al., 1997] and precise clocks and orbits from NASA-JPL (see auxiliary material for more details). The data were referenced to the International Terrestrial Reference Frame 2008 (ITRF08) frame, and then transformed to both NA and CA reference frames (Table S2) with an updated version of the NA and CA ITRF08 Euler poles (C. DeMets, personal communication, 2011).

[7] The cGPS data do not show evidence for transient deformation associated with slow-slip events (Figure S1) despite abundant swarms north of Puerto Rico and the Virgin Islands (PRVI) since March 2007. Only three M >7 earthquakes occurred within the network region in the past 200 years, the last one in 1943 (Figure 1) [ten Brink et al., 2011], thus the contribution to the velocity field from postseismic slip is likely negligible.

[8] In the next section we model 10 of the 13 GPS sites. Velocities of 9 sites from St. Maarten to western Puerto Rico range between $0.8 \mathrm{~mm} / \mathrm{yr}$ to $2.5 \mathrm{~mm} / \mathrm{yr}$ toward the NW in a CA reference frame (Figure 1 and Table S1). The 10th site, CRO1, is almost stationary. Three sites were not modeled.
STVI is located only $650 \mathrm{~m}$ away from VITH but has a very different velocity. We preferred to model VITH rather than STVI for two reasons: (1) STVI has been in operation for half the time period of VITH, and (2) VITH and CUPR have similar velocities. Two sites in the SW part of the network (MOPR and PRMI) have very different velocity vectors from the rest of the network and are not included in the models. These sites likely reflect real motion and not monument noise, because their velocity vectors are similar to each other (MOPR: $1.7 \mathrm{~mm} / \mathrm{y}, 228^{\circ}$; PRMI: $2.3 \mathrm{~mm} / \mathrm{y}, 235^{\circ}$ ) and to those in easternmost Hispaniola [Calais et al., 2010]. Geological interpretation of this SW motion is discussed later.

\section{Models}

[9] We model the interseismic strain accumulation using Coulomb3.1 elastic half-space model [Lin and Stein, 2004; Toda et al., 2005]. The seismogenic zone was divided into 4 segments, S1-S4 (Table S3, and semi-transparent rectangles in Figure 1) to fit the curved plate boundary and the contributions from all the segments were summed for each site. The segments extend beyond the GPS sites to ensure that the calculated vectors are not affected by edge effects. The geometry of the subduction zone in this region is poorly known because of the paucity of interplate earthquakes and the lack of detailed seismic refraction profiles across the forearc and the arc. Consequently, the number of model parameters, $k=28$ (4 segments each having 2 location points, updip and downdip depths, dip, and 2 backslip vectors) exceeds the number of observations $(j=20)$. Our starting model placed the seismogenic zone (i.e., the zone of coupling) in the forearc beginning $\sim 40 \mathrm{~km}$ from the trench with up-dip and down-dip limits of $10 \mathrm{~km}$ and $35 \mathrm{~km}$, respectively, and a downdip width of $80 \mathrm{~km}$. Model fit was

Figure 1. (a) Shaded and colored bathymetry of the NE Caribbean. See inset for location. Arrows are observed (red) and calculated (blue) velocities relative to CA plate reference with their error ellipse (Table S1). Semi-transparent rectangles S1-S4 are the locations of surface projections of patches on which backslip was applied. Values of trench-parallel and perpendicular components of the backslip and their percentage of the respective plate convergence components are given for the preferred model. Yellow-dashed rectangles N1-N4 - Locations of 40-km-wide modeled patches close to the trench with dip slip component, discussed in the text. Cross-section in inset shows model geometry. Barbed lines, dashed lines, and solid lines - thrust, strike-slip, and normal faults, respectively. Dashed red line - interpreted boundary between Hispaniola-Mona Passage region, which moves to the SW, and PRVI, which moves to the NW, in a CA plate reference. Yellow stars - Large $(\mathrm{M}>7)$ historical earthquakes and the year they occurred. (b) Observed total velocity magnitude (black dots) and the East component of the velocity (red dots) of the 10 modeled cGPS sites as a function of distance of sites from the trench. Black and red error bars - Average radii of error ellipses, and the radii of minor axes of the error ellipses, respectively (see Table S1). (c) Plot to test possible counter-clockwise rotation of PRVI. Blue dots - Observed N-component of velocity of 8 cGPS sites as a function of distance of sites east from western tip of Puerto Rico. Sites SMRT and CRO1 were not plotted because they are outside the proposed rotated block [Manaker et al., 2008]. Green dots - Residual N-velocity components after applying a model with trench-perpendicular convergent backslip with 30\% locking on segments S1-S3 (see text for further discussion). (d) Variations in model fit as a function of varying slab depth (red line) and dip (blue line). Dip and depth were varied in all segments in unison. Model fit is described by weighted least square estimator (WLSE, see text) and normalized to fit of model marked 3, with parameters described in text. Models above dashed line are statistically different than model 3 at significance level $\alpha=0.05$. Model marked 2 - same as model 3 except for uniform dip of $16^{\circ}$ and down-dip width of $90 \mathrm{~km}$. Model marked 1 - best-fit model with geometry and slip parameters shown in Figure 1a. (e) Model 1 with SMRT excluded to test how well the remaining GPS sites constrain slip parameters on segment S4 (Lesser Antilles). Trench-perpendicular thrust was imposed on that segment at the rate predicted by plate motion (Table S3) multiplied by varying coupling fraction. Curve shows fit of these models normalized to fit of model 1 and their statistical significance (dashed line). (f) Test of sensitivity of the geodetic network to possible near-trench thrust slip accumulation. Trench-perpendicular slip was imposed on rectangles N1-N4 in Figure 1a at a fraction of the rates predicted by plate motion (Table S3). The coupling fraction was varied from 0 to 1 and the model fits were normalized to model 1 with no coupling on N1-N4. Models above dashed line are statistically different than model 1 at $\alpha=0.05$. 
evaluated by the minimization of the weighted least square estimate or (WLSE)

$$
W L S E(k)=\sum_{j=1}^{20}\left(\frac{\left(Y_{j}-m_{j}(k)\right)^{2}}{\sigma_{j}^{2}}\right)
$$

where, $Y_{j}$ and $m_{j}(k)$ are the observations and model predictions, $j=1,2, .20$ are the $\mathrm{N}$ or $\mathrm{E}$ component of the $10 \mathrm{GPS}$ sites, which are assumed to be mutually independent, and $\sigma^{2}$ are variances in the observations, which include both the uncertainty of measurement and the uncertainty in the CA Euler vector. An acceptable model also had to qualitatively display a normal distribution of $\left(Y_{j}-m_{j}(k)\right)$.

[10] Once an approximate set of backslip displacement parameters was found, we varied the dip and depth of the seismogenic zone and occasionally adjusted the backslip to achieve a better fit. Our best-fit model (WLSE $=23.88$, marked as 1 in Figure 1d; slip parameters shown in Figure 1) comprises 3 segments north of PRVI (S1-S3) with an 80-kmwide seismogenic zone and a dip of $18^{\circ}$ toward the south. Segment 4 (S4 - Lesser Antilles) has a 90-km-wide seismogenic zone with a dip of $16^{\circ}$. A wider seismogenic zone with a gentler $\left(16^{\circ}\right)$ slope off the Lesser Antilles than north of PRVI, is compatible with the larger distance between the trench and the arc at this location and with a published crosssection from gravity modeling [Westbrook and McCann, 1986]. Slightly less favorable models are ones where all 4 segments have a dip of $16^{\circ}$ and a uniform down-dip width of $90 \mathrm{~km}(\mathrm{WLSE}=25.36)$ and a model with a dip of $18^{\circ}$ and a uniform down-dip width of $80 \mathrm{~km}(\mathrm{WLSE}=26.92)$ (marked 2 and 3 in Figure 1d).

[11] A modified likelihood ratio statistic was applied that investigates model sensitivity to varying one parameter of interest, $\beta$, at a time, and comparing WLSE with that of a reference model, $\beta_{0}$. Models with $\beta \neq \beta_{0}$ can be rejected at $\alpha=0.05$ significance level, if $\Delta$ exceeds the upper $\alpha$ quantile of the $\chi^{2}$ distribution with 1 degree of freedom.

$$
\Delta=2\left(\operatorname{WLSE}\left(k\left(\beta_{0}\right)\right)-\operatorname{WLSE}(k)\right)
$$

Figure 1d shows an example where models with different depths and constant dips were compared to the model marked 3 described above. Models with depths within 10 $35 \mathrm{~km} \pm 4 \mathrm{~km}$ and dips within $18^{\circ} \pm 3^{\circ}$ could not be rejected at $\alpha=0.05$, and are therefore as statistically valid as model 3 .

[12] The best-fit model requires backslip in an opposite direction to subduction north of PRVI, namely, trenchperpendicular divergence rather than the expected convergence. A model without divergence on $\mathrm{S} 1-\mathrm{S} 3$ can be rejected at $\alpha=0.001$. The absence of trench-perpendicular convergence seaward of the network is unusual considering that oblique subduction zones such as Sumatra show a subduction-directed component [Prawirodirdjo et al., 1997]. In contrast, 6 of our cGPS sites have a trenchward component $>0.6 \pm 0.2 \mathrm{~mm} / \mathrm{y}, 2$ of which are $>1 \pm 0.2 \mathrm{~mm} / \mathrm{y}$ (Figure 1c and Table S1).

[13] No divergence or convergence is modeled on S4, but it could be argued that modeled backslip for this segment is constrained by only one site, SMRT. To test this argument, we imposed on S4 the expected trench-perpendicular convergence component from relative plate motion with various percentage of locking and examined the fit to the other 9
cGPS sites (i.e., without SMRT). The fit degrades rapidly with increasing coupling on S4, but trench-perpendicular locking of $<30 \%$ on this segment $(<3.2 \mathrm{~mm} / \mathrm{y})$ could not be rejected $\alpha=0.05$ (Figure 1e). The presence of shallow forearc thrust earthquakes of $\mathrm{M}_{\mathrm{w}}<6$ in the northern Lesser Antilles [López et al., 2006] suggests some coupling of the subduction interface there. Additional GPS sites are needed in this region to better constrain the elastic strain accumulation.

[14] The contribution of a coupled slab segment (or any fault) to geodetic models falls off with distance from the observations [Savage, 1983]. As the 1896 Sanriku and the 2011 Tohoku-Oki earthquakes have shown, strain accumulation near the trench can result in significant earthquakes and tsunamis [Simons et al., 2011, and references therein]. To test whether convergent strain accumulation in the NE Caribbean is not detected because of its distance from the cGPS network, we applied trench-perpendicular convergence in a $40-\mathrm{km}$-wide region closest to the trench. The near-trench region with water depth of 7-8 km, was represented by 4 segments (yellow dashed rectangles N1-N4 in Figure 1) with a dip of $6^{\circ}$ and an up-dip and down-dip depths of 8 and $12 \mathrm{~km}$, respectively. The applied backslip is proportional to the trench-perpendicular convergent plate component of each segment (Table S3), and was multiplied by a fraction between $0-1$ to represent the magnitude of locking. As before, the contributions of all 4 segments were summed for each modeled site. The fit appears to decrease with increasing fraction of inter-plate coupling (Figure 1f), but the accumulation of up to $33 \%$ of the convergent plate component near the trench $(<1.1,1.1,1.9$, and $3.5 \mathrm{~mm} / \mathrm{y}$ for $\mathrm{S} 1, \mathrm{~S} 2, \mathrm{~S} 3$, and S4, respectively) cannot be rejected at $\alpha=0.05$. There have been several M 5-6 earthquakes north of PRVI with very oblique thrust mechanisms $\left(10^{\circ}-20^{\circ}\right.$ from plate motion direction), mostly located closer to the cGPS sites than to the trench [Doser et al., 2005], but their causes are presently unknown.

[15] Therefore, within the framework of our model assumptions, the observed motion in Puerto Rico, the Virgin Islands, and northern Lesser Antilles does not require trenchperpendicular convergence although a small percentage of locking close to the trench and in the forearc of the Lesser Antilles cannot be rejected. The region north of Puerto Rico may actually be extending slightly, as has been suggested by Speed and Larue [1991].

\section{Discussion}

[16] Causes for the absence of subduction-directed motion, particularly north of PRVI are further investigated below. One possible cause is a coherent bias in the cGPS results, perhaps due to inaccurate CA plate reference. However, this is unlikely because multiple studies have yielded similar CA Euler vectors (Table S2). Another possibility is that the cGPS vectors represent a combination of trench-perpendicular convergence and a much larger signal of regional rotation or translation of the upper plate, as was deduced for the Cascadia margin in Oregon [McCaffrey et al., 2000]. Mann et al. [2002] qualitatively proposed counter-clockwise (CCW) rotation of PRVI around a hinge in Mona Passage, caused by the collision of the Bahamas Platform with the Caribbean arc, but could not determine if it continues today. Present-day rotation of PRVI of the kind proposed by Mann et al. should 
be expressed in the GPS data as an increase in the $\mathrm{N}$ component as a function of site distance eastward from Mona Passage. While a subset of the network (PUR5, P780, MIPR, ZSU1, and CUPR) shows such increase that can be interpreted as $\mathrm{CCW}$ rotation around a pole at $67.10 \mathrm{~W}^{\circ}, 16.61 \mathrm{~N}^{\circ}$ $(\omega=0.414 \pm 0.250 \mathrm{deg} / \mathrm{m} . \mathrm{y}$.$) , the trend becomes ambiguous$ when other sites are included $\left(68.71 \mathrm{~W}^{\circ}, 12.65 \mathrm{~N}^{\circ}\right.$, $\omega=0.123 \pm 0.127 \mathrm{deg} / \mathrm{m} . \mathrm{y}$. ) (Figure 1c). It could be argued that, as in Cascadia, the observed velocity is a combination of $\mathrm{CCW}$ rotation and trench-perpendicular convergence. To test this argument, we imposed on segments S1-S3 the trenchperpendicular convergent backslip from plate motion with $30 \%$ locking. In such model, the $\mathrm{N}$ velocity due to $\mathrm{CCW}$ rotation is the difference between the observed and calculated $\mathrm{N}$ components. The trend remains ambiguous even when convergence is imposed (green dots in Figure $1 \mathrm{c} ; 76.68^{\circ} \mathrm{W}$, $\left.16.73^{\circ} \mathrm{N}, \omega=0.044 \pm 0.052 \mathrm{deg} / \mathrm{m} . \mathrm{y}.\right)$, suggesting that the NW velocity is not due to PRVI rotation.

[17] We suggest that plate divergence north of PRVI may result from slab retreat and or a tear in the slab [ten Brink, 2005]. The maximum divergence $(3 \mathrm{~mm} / \mathrm{y})$ is modeled in S2, where geological evidence for possible extension includes unusually deep $(>7500 \mathrm{~m})$ forearc, very low $(-380 \mathrm{mGal})$ free-air gravity anomaly, and a northward-tilting carbonate platform [ten Brink, 2005]. The carbonate platform was formed near sea level and is now up to $4000 \mathrm{~m}$ deep.

[18] We next focus the discussion on the trench-parallel component of the cGPS data, which is generally larger than the trench-perpendicular component (compare Figures 1b and 1c). The magnitude of the trench-parallel component decreases with distance from the trench (Figure 1b) mimicking the total vector magnitude. Negredo et al. [2004] suggested that an eastward asthenoshperic flow at the base of the CA plate drags the plate eastward. van Benthem and Govers [2010] argued that the eastward motion is driven by suction force due to slab retreat of the Lesser Antilles subduction zone south of Guadeloupe. The eastward motion is resisted by friction on the plate boundaries [Negredo et al., 2004] or more specifically, by sticky points, such as the Bahamas Platform north of Hispaniola and a few volcanic ridges farther east [van Benthem and Govers, 2010]. This resistance creates a strong velocity gradient inward of the plate boundary, which in CA reference is expressed as decreasing westward velocity toward the plate interior (Figure 1b). If resistance along the NE Caribbean is provided mostly by the Bahamas platform [Mann et al., 2002], then PRVI could be dragged westward with Hispaniola only if the Greater Antilles oceanic island arc is rigid enough to transfer some of the force along the arc. The decreasing fraction of trench-parallel locking in the best-fit model from $50 \%$ in western Puerto Rico to $0 \%$ north of the Virgin Islands may be representative of this westward drag. The large trench-parallel component of S4 is compatible with geological and seismological inferences for trench-parallel extensional deformation of the northern Lesser Antilles arc [Feuillet et al., 2002; López et al., 2006].

[19] Sites MOPR (Mona Island) and PRMI (SW Puerto Rico) move to the SW similar to GPS sites in Hispaniola, and unlike the NW-directed motion of the rest of the network (Figure 1) [López et al., 2011]. Velocities in Hispaniola increase westward from values similar to our observations in Mona Passage, to $>10 \mathrm{~mm} / \mathrm{y}$ in central Hispaniola [Calais et al., 2010]. Our suggested boundary between Hispaniola and the PRVI, marked by heavy dashed red line in Figure 1, may extend north to Mona rift. The $1918 \mathrm{Mw} 7.2$ [Doser et al., 2005] earthquake could have originated on this boundary. Abundant shallow seismicity in SW Puerto Rico shows mixed left-lateral strike slip and NNE-SSW extension [Huérfano et al., 2005]. The seismicity and active faults in SW Puerto Rico [Prentice and Mann, 2005] and within Mona Passage (Figure 1) probably reflect NE-SW opening of Mona Passage [Chaytor and ten Brink, 2010]. The relative motion across this boundary can be estimated from the difference in velocity between MOPR and PUR5 $\left(1.9 \mathrm{~mm} / \mathrm{y}\right.$ in direction $\left.220^{\circ}\right)$ or between PRMI and P780 (3.1 mm/y in direction $\left.241^{\circ}\right)$ as SW-NE and not E-W as previously suggested [Jansma et al., 2000].

\section{Conclusions}

[20] It is difficult to reconcile NW-directed cGPS velocities in Puerto Rico, Virgin Islands, and St. Maarten, with accumulation of trench-perpendicular thrust on a locked subduction interface, unless the locking percentage is low in the northern Lesser Antilles, and in the trench-proximal region north of PRVI. The data may in fact suggest that most of the interface north of PRVI is extending in agreement with abnormal bathymetry, gravity, and subsidence there. The trench-parallel component of the cGPS velocity decreases gradually away from the trench, indicating an eastward motion of the interior CA plate relative to its northern boundary. Thus, if the cGPS data reflect the magnitude of coupling on the subduction interface, the subduction zone north of PRVI probably cannot generate mega-earthquakes, although damaging smaller earthquakes cannot be discounted. GPS velocity vectors in Mona Passage and SW Puerto Rico are directed southwestward relative to CA plate similar to GPS vectors in eastern Hispaniola and unlike those in PRVI, implying at least $2-3 \mathrm{~mm} / \mathrm{y}$ of NE-SW extension across SW Puerto Rico and Mona Passage.

[21] Acknowledgments. We thank technicians from the Puerto Rico Seismic Network, and James Normandeau from UNAVCO for technical help with stations. Tim Dixon and Yan Jiang for technical help with GPS data processing, Andy Solow for help with statistical analysis, and Brian Andrews, for help with Figure 1. Thoughtful reviews by Andrew Freed, Daniel Brothers, John Weber, and an anonymous reviewer are gratefully acknowledged.

[22] The Editor thanks John Weber and an anonymous reviewer for assisting with the evaluation of this paper.

\section{References}

Atwater, B. F., U. S. ten Brink, M. Buckley, R. S. Halley, B. E. Jaffe, A. M. López-Venegas, E. G. Reinhardt, M. P. Tuttle, S. Watt, and Y. Wei (2012), Geomorphic and stratigraphic evidence for an unusual tsunami or storm a few centuries ago at Anegada, British Virgin Islands, Nat. Hazards, doi:10.1007/s11069-010-9622-6, in press.

Calais, E., A. Freed, G. Mattioli, F. Amelung, S. Jónsson, P. Jansma, S. H. Hong, T. Dixon, C. Prépetit, and R. Momplaisir (2010), Transpressional rupture of an unmapped fault during the 2010 Haiti earthquake, Nat. Geosci., 3, 794-799, doi:10.1038/ngeo992.

Chaytor, J. D., and U. S. ten Brink (2010), Extension in Mona Passage, northeast Caribbean, Tectonophysics, 493, 74-92, doi:10.1016/j. tecto.2010.07.002.

DeMets, C., R. G. Gordon, and D. F. Argus (2010), Geologically current plate motions, Geophys. J. Int., 181, 1-80, doi:10.1111/j.1365246X.2009.04491.x.

Dixon, T. H. (1993), GPS measurement of relative motion of the Cocos and Caribbean plates and strain accumulation across the Middle America trench, Geophys. Res. Lett., 20, 2167-2170, doi:10.1029/93GL02415.

Doser, D. I., C. M. Rodriguez, and C. Flores (2005), Historical earthquakes of the Puerto Rico-Virgin Islands region (1915-1963), in Active 
Tectonics and Seismic Hazards of Puerto Rico, the Virgin Islands, and Offshore Areas, edited by P. Mann, Spec. Pap. Geol. Soc. Am., 385, 103-114.

Feuillet, N., I. Manighetti, P. Tapponnier, and E. Jacques (2002), Arc parallel extension and localization of volcanic complexes in Guadeloupe, Lesser Antilles, J. Geophys. Res., 107(B12), 2331, doi:10.1029/ 2001JB000308.

Geist, E. L., and T. Parsons (2009), Assessment of source probabilities for potential tsunamis affecting the U.S. Atlantic coast, Mar. Geol., 264, 98-108, doi:10.1016/j.margeo.2008.08.005.

Hashimoto, C., A. Noda, T. Sagiya, and M. Matsu'ura (2009), Interplate seismogenic zones along the Kuril-Japan trench inferred from GPS data inversion, Nat. Geosci., 2, 141-144, doi:10.1038/ngeo421.

Huérfano, V., C. von Hillebrandt-Andrade, and G. Baez-Sanchez (2005), Microseismic activity reveals two stress regimes in southwestern Puerto Rico, in Active Tectonics and Seismic Hazards of Puerto Rico, the Virgin Islands, and Offshore Areas, edited by P. Mann, Spec. Pap. Geol. Soc. Am., 385, 81-101.

Jansma, P. E., and G. S. Mattioli (2005), GPS results from Puerto Rico and the Virgin Islands: Constraints on tectonic setting and rates of active faulting, in Active Tectonics and Seismic Hazards of Puerto Rico, the Virgin Islands, and Offshore Areas, edited by P. Mann, Spec. Pap. Geol. Soc. Am., 385, 13-30.

Jansma, P. E., G. S. Mattioli, A. López, C. DeMets, T. H. Dixon, P. Mann, and E. Calais (2000), Neotectonics of Puerto Rico and the Virgin Islands, northeastern Caribbean, from GPS geodesy, Tectonics, 19, 1021-1037, doi:10.1029/1999TC001170.

Lin, J., and R. S. Stein (2004), Stress triggering in thrust and subduction earthquakes and stress interaction between the southern San Andreas and nearby thrust and strike-slip faults, J. Geophys. Res., 109, B02303, doi:10.1029/2003JB002607.

López, A. M., S. Stein, T. Dixon, G. Sella, E. Calais, P. Jansma, J. Weber, and P. LaFemina (2006), Is there a northern Lesser Antilles forearc block?, Geophys. Res. Lett., 33, L07313, doi:10.1029/2005GL025293.

López, A. M., P. E. Jansma, G. S. Mattioli, S. A. James, D. Ihemedu, S. M. Quintana, and J. S. Salazar (2011), Constraining Puerto Rico-Virgin Islands microplate internal deformation with two decades of GPS observations, Abstract T23D-2450 presented at Fall Meeting, AGU, San Francisco, Calif., 5-9 Dec.

Manaker, D. M., E. Calais, A. M. Freed, S. T. Ali, P. Przybylski, G. Mattioli, P. Jansma, C. Pre'petit, and J. B. deChabalier (2008), Interseismic plate coupling and strain partioning in the northeastern Caribbean, Geophys. J. Int., 174, 889-903, doi:10.1111/j.1365-246X.2008.03819.x.

Mann, P., E. Calais, J.-C. Ruegg, C. DeMets, P. E. Jansma, and G. S. Mattioli (2002), Oblique collision in the northeastern Caribbean from GPS measurements and geological observations, Tectonics, 21(6), 1057, doi:10.1029/ 2001 TC001304.

McCaffrey, R., M. D. Long, C. Goldfinger, P. C. Zwick, J. L. Nabelek, C. K. Johnson, and C. Smith (2000), Rotation and plate locking at the southern Cascadia subduction zone, Geophys. Res. Lett., 27, 3117-3120, doi:10.1029/2000GL011768.

Negredo, A. M., I. Jiménez-Munt, and A. Villaseñor (2004), Evidence for eastward mantle flow beneath the Caribbean plate from neotectonic modeling, Geophys. Res. Lett., 31, L06615, doi:10.1029/2003GL019315.

Norabuena, E., L. Leffler-Griffin, A. Mao, T. Dixon, S. Stein, I. S. Sacks, L. Ocola, and M. Ellis (1998), Space geodetic observations of NazcaSouth America convergence across the central Andes, Science, 279, 358-362, doi:10.1126/science.279.5349.358.

Prawirodirdjo, L., et al. (1997), Geodetic observations of interseismic strain segmentation at the Sumatra Subduction Zone, Geophys. Res. Lett., 24(21), 2601-2604, doi:10.1029/97GL52691.

Prentice, C. S., and P. Mann (2005), Paleoseismic study of the South Lajas fault: First documentation of onshore Holocene fault in Puerto Rico, in Active Tectonics and Seismic Hazards of Puerto Rico, the Virgin Islands, and Offshore Areas, edited by P. Mann, Spec. Pap. Geol. Soc. Am., 385, 215-222.

Savage, J. C. (1983), A dislocation model of strain accumulation and release at a subduction zone, J. Geophys. Res., 88, 4984-4996, doi:10.1029/ JB088iB06p04984.

Simons, M., et al. (2011), The 2011 magnitude 9.0 Tohoku-Oki earthquake: Mosaicking the megathrust from seconds to centuries, Science, 332, 1421-1425, doi:10.1126/science. 1206731.

Speed, R. C., and D. K. Larue (1991), Extension and transtension in the plate boundary zone of the northeastern Caribbean, Geophys. Res. Lett., 18, 573-576, doi:10.1029/91GL00394.

ten Brink, U. (2005), Vertical motions of the Puerto Rico Trench and Puerto Rico and their cause, J. Geophys. Res., 110, B06404, doi:10.1029/ 2004JB003459.

ten Brink, U., W. H. Bakun, and C. H. Flores (2011), Historical perspective on seismic hazard to Hispaniola and the northeast Caribbean region, J. Geophys. Res., 116, B12318, doi:10.1029/2011JB008497.

Toda, S., R. S. Stein, K. Richards-Dinger, and S. B. Bozkurt (2005), Forecasting the evolution of seismicity in Southern California: Animations built on earthquake stress transfer, J. Geophys. Res., 110, B05S16, doi:10.1029/2004JB003415.

van Benthem, S., and R. Govers (2010), The Caribbean plate: Pulled, pushed, or dragged?, J. Geophys. Res., 115, B10409, doi:10.1029/ 2009JB006950.

Westbrook, G. K., and W. R. McCann (1986), Subduction of Atlantic lithosphere beneath the Caribbean, in The Geology of North America, vol. H, The Caribbean Region, edited by G. Dengo and J. E. Case, pp. 341-350, Geol. Soc. of Am., Boulder, Colo.

Zumberge, J. F., M. B. Heflin, D. C. Jefferson, M. M. Watkins, and F. H. Webb (1997), Precise point positioning for the efficient and robust analysis of GPS data from large networks, J. Geophys. Res., 102(B3), 5005-5017, doi:10.1029/96JB03860. 